Research Article

\title{
Coupling Effect of Metals and Oxides on the Oxygen Supply Performance of Sodium Chlorate Oxygen Candle
}

\author{
Na Gao, ${ }^{1,2,3}$ Chunguo Ma $\mathbb{D}^{1},{ }^{1,2,3}$ Kaeryaer Kariman, ${ }^{1,2,3}$ Jianguo Liu, ${ }^{1,2,3}$ Zheng Zhang, ${ }^{1,2,3}$ \\ Yaqing Dai, ${ }^{1,2,3}$ and Zhao Wang ${ }^{1,2,3}$ \\ ${ }^{1}$ School of Civil and Resource Engineering, University of Science and Technology Beijing, Beijing 100083, China \\ ${ }^{2}$ Key Laboratory of High-Efcient Mining and Safety of Metal Mines of the Ministry of Education, \\ University of Science and Technology Beijing, Beijing 100083, China \\ ${ }^{3}$ Mine Emergency Technology Research Center, University of Science and Technology Beijing, Beijing 100083, China \\ Correspondence should be addressed to Chunguo Ma; mcg970318@163.com
}

Received 13 September 2021; Accepted 10 November 2021; Published 26 November 2021

Academic Editor: Josefina Pons

Copyright (C) $2021 \mathrm{Na}$ Gao et al. This is an open access article distributed under the Creative Commons Attribution License, which permits unrestricted use, distribution, and reproduction in any medium, provided the original work is properly cited.

\begin{abstract}
In this study, to explore the influence of metals and oxides on the oxygen production rate and stability of sodium chlorate oxygen candles, 28 experimental samples were investigated. The effects of $\mathrm{Co}_{2} \mathrm{O}_{3}, \mathrm{Co}_{3} \mathrm{O}_{4}$, and $\mathrm{Fe}_{2} \mathrm{O}_{3}$ with different mass fractions on the thermal decomposition temperature and thermal decomposition rate of sodium chlorate were compared and analyzed. $\mathrm{Co}_{3} \mathrm{O}_{4}$ (5\%) was obtained to reduce the thermal decomposition range to $260-450^{\circ} \mathrm{C}$ and reduce the pyrolysis interval $\Delta T$ to $46.2^{\circ} \mathrm{C}$. Through the development of three metals ( $\mathrm{Fe}, \mathrm{Mg}$, and $\mathrm{Mn}$ ), under four mass fractions $\left(2 \%, 4 \%, 6 \%\right.$, and $8 \%$ ) mixed with $\mathrm{Co}_{3} \mathrm{O}_{4}$ (5\%), the results of the effective oxygen production efficiency test for the thermal decomposition reaction of sodium chlorate demonstrated that $\mathrm{Mn}(6 \%)-\mathrm{Co}_{3} \mathrm{O}_{4}(5 \%)$ exhibited the best catalytic and heat coupling effect; the effective oxygen production efficiency of $97.8 \%$ was achieved. Oxygen candle oxygen supply experiment was conducted; the oxygen candle composition for the test was determined to be $\mathrm{NaClO}_{3}(86 \%), \mathrm{Mn}(6 \%), \mathrm{Co}_{3} \mathrm{O}_{4}(5 \%)$, and kaolin (3\%); in the four stages of the oxygen candle oxygen supply reaction test, the average oxygen supply rate reached $1.647 \mathrm{~L} / \mathrm{min}$, actual oxygen production was $28 \mathrm{~L}$, and effective oxygen production rate of the oxygen candle was $53.6 \%$. An increase of $9 \%$ was observed compared to the previous similar studies. The results of this study present a formula to optimize the oxygen supply of the oxygen candle, which is crucial for improving the oxygen supply performance of the oxygen candle.
\end{abstract}

\section{Introduction}

Oxygen candle, a solid oxygen source, possesses several advantages, such as high and fast oxygen production and large unit volume storage capacity; in addition, it has the advantages of unnecessity of additional power during use, stable usage volume, and easy to store and transport. Furthermore, the oxygen production and production rate of the oxygen candle are not affected by changes in the ambient temperature, humidity, and pressure [1-3]. Therefore, oxygen candles have been widely employed in aviation, submarine, mine rescue, and other fields [4].

Significant progress has been made in the research field of oxygen candles by various domestic and international researchers. Comparing the performance of common oxygen supply methods, Yajuan et al. analyzed the applicability of oxygen candles on plateaus [5]. Lei et al. analyzed the feasibility of the application of oxygen candles in deep-sea manned submersibles and proposed technical indicators suitable for emergency oxygen supply in deep-sea manned submersibles [6]. Shu et al. conducted a series of simulation tests and discussed the impact of oxygen candles on the living environment of a mining hazard space [7]. Shafirovich et al. used differential thermal analysis (DTA)/thermogravimetric analyzer (TGA) combined thermogravimetric analysis to conduct a binary thermogravimetric analysis of five common metals- $\mathrm{Al}, \mathrm{Fe}, \mathrm{Co}, \mathrm{Ni}$, and $\mathrm{Sn}-$ and $\mathrm{NaClO}_{3}$; they investigated the catalytic effects of five metals on the 
thermal decomposition of $\mathrm{NaClO}_{3}[8]$. Gao and Liu $[9,10]$ optimized the oxygen production technology of the chlorate oxygen candle; in particular, they optimized the working principle, raw materials, and starting method [9] and studied the influence of manganese metal fuel on the pyrolysis of sodium chlorate oxygen candle [10].

The existing research results in this field are mainly to analyze the influence of single factor on the catalytic effect and technical index of oxygen candle. The coupling effect of metal and oxide on the oxygen supply performance of oxygen candles and the oxygen supply efficiency in closed space are lacking. Based on the previous research results and the oxygen production mechanism of $\mathrm{NaClO}_{3}$ pyrolysis, the effects of oxides $\left(\mathrm{Co}_{2} \mathrm{O}_{3}, \mathrm{Co}_{3} \mathrm{O}_{4}\right.$, and $\left.\mathrm{Fe}_{2} \mathrm{O}_{3}\right)$ and metals $(\mathrm{Fe}, \mathrm{Mg}$, and $\mathrm{Mn})$ on the pyrolysis of $\mathrm{NaClO}_{3}$ were compared and analyzed by thermogravimetric experiment. An optimized formula of oxygen candle with higher efficiency and better catalytic performance than the previous research was proposed, and the application effect of oxygen candle oxygen supply was verified by the oxygen candle oxygen supply test. The research conclusions provide a reference for improving the multifactor coupling oxygen supply performance of sodium chlorate oxygen candle.

\section{Materials}

\subsection{Test Reagents and Instruments}

2.1.1. Test Reagents. $\mathrm{NaClO}_{3}$, analytically pure, $\mathrm{Fe}, \mathrm{Mg}$, and $\mathrm{Mn}$ were purchased from Beijing Tongguang Fine Chemical Co., Ltd. $\mathrm{Co}_{2} \mathrm{O}_{3}$ (99.9\%), $\mathrm{Co}_{3} \mathrm{O}_{4}(99.9 \%), \mathrm{Fe}_{2} \mathrm{O}_{3}$ (99.9\%), and kaolin were purchased from Beijing Yihua Chengda Technology Co., Ltd. Silica aerogel felt insulation material was purchased from Zhongwei (Tianjin) Technology Co., Ltd.

2.1.2. Test Instruments. The test instruments include the constant temperature drying oven (DHG-9070A, Shanghai Jinghong Experimental Equipment Co., Ltd.), omni-directional planetary ball mill (QM-QX10, Nanjing University Instrument Factory), pressure testing machine (YES-300, Jinan Huaxing Experimental Equipment Co., Ltd.), thermal heavy mass spectrometer (STA449F3A-0660-M, Netzsch, Germany), and multifunction gas detector (Anpal Technology Co., Ltd.).

\subsection{Experimental Methods}

\subsubsection{Sample Preparation}

Thermal Decomposition Reaction. To avoid the influence of free water vapor in the medicine on the test, $\mathrm{NaClO}_{3}$ was placed in a constant temperature drying oven at $80^{\circ} \mathrm{C}$ for $8 \mathrm{~h}$ before sample preparation; the sample proportioning was performed according to Table 1 . We added $10 \mathrm{~g}$ of the proportioned sample to the ceramic crucible and manually stirred it for $10 \mathrm{~min}$. A total of 28 samples were prepared.

Oxygen Candle Oxygen Supply Reaction. Based on the previous research results, the oxygen candle composition for the test was determined to be $\mathrm{NaClO}_{3}$ (86\%), Mn (6\%), $\mathrm{Co}_{3} \mathrm{O}_{4}(5 \%)$, and kaolin (3\%). The oxygen candle structure adopts a hollow structure, which promotes the reaction [11]. The composition, mass (Table 2), and size (inner diameter: $10 \mathrm{~mm}$, outer diameter: $60 \mathrm{~mm}$, and height: $64.5 \mathrm{~mm}$ ) of the oxygen candle for the test can be calculated according to equations (1) and (2).

Theoretical Oxygen Supply of Oxygen Candle for Test. The absolute value of the maximum oxygen uptake of healthy adult men in China is $3.0 \mathrm{~L} / \mathrm{min}-3.5 \mathrm{~L} / \mathrm{min}$; we assumed the uptake value as $3.5 \mathrm{~L} / \mathrm{min}$ to prepare a sufficient amount of oxygen. Considering the influence of the volume of the oxygen candle during the oxygen supply test, to meet the 15 min oxygen demand of a healthy adult male, we determined an appropriate size for the oxygen candle during preparation. The oxygen demand calculation is as follows.

$$
V_{15 \min }=V_{\text {max }} \times t=3.5 \times 15=52.5 L .
$$

where $V_{15 \min }$ is the 15 min oxygen demand of healthy adult men, $V_{n}$ is the absolute value of the maximum oxygen uptake, and $t$ is the maximum oxygen uptake time.

Composition and Quality of Oxygen Candle for Test. According to the main reaction equation of the oxygen candle production, the mass of the oxygen candle sample required to produce $52.5 \mathrm{~L}$ of oxygen was calculated, as given in Table 2.

Oxygen Candle Volume Size for Test. The density of the oxygen candle compressed by the oxygen candle selected in this test was in the range of $1.8 \mathrm{~g} / \mathrm{cm}^{3}-2.0 \mathrm{~g} / \mathrm{cm}^{3}$, and the quality of the medicine required for the test was $318 \mathrm{~g}$. According to equation (2), the volume of the oxygen candle required for an adult to breathe for 15 minutes was $176.7 \mathrm{~cm}^{3}$, inner diameter of the oxygen candle was $10 \mathrm{~mm}$, outer diameter was $60 \mathrm{~mm}$, and height was $64.5 \mathrm{~mm}$.

$$
V_{\text {Oxygen }}=\frac{m}{\rho},
$$

where, $V_{\text {Oxygen }}$ is the volume of the oxygen candle sample, $m$ is the mass of the oxygen candle sample, and $\rho$ is the density of the oxygen candle sample.

We used an omni-directional planetary ball mill to grind and mix the sample for $5 \mathrm{~min}$ at a speed of $280 \mathrm{rpm}$ and placed the ground oxygen candle sample into a self-made compression mold as shown in Figure 1. Subsequently, we used a pressure testing machine to pressurize the sample with a force of $35 \mathrm{KN}$. The oxygen candle body for the test was obtained from the mold [12], as shown in Figure 2.

\subsubsection{Thermal Decomposition Reaction Test. We used} Netzsch STA449F3A-0660-M thermogravimetric-mass spectrometry combined analysis equipment to perform thermal decomposition reaction tests on 28 samples. Herein, $15 \pm 2 \mathrm{mg}$ of each group of samples was weighed each time and placed in the thermogravimetric analyzer; subsequently, thermogravimetric analysis was conducted. The starting 
TABle 1: Proportioning table for the thermogravimetric experiment.

\begin{tabular}{|c|c|c|c|c|c|c|c|c|}
\hline \multirow{2}{*}{ Sample } & \multirow{2}{*}{$\mathrm{NaClO}_{3}$} & \multirow{2}{*}{$\mathrm{Co}_{2} \mathrm{O}_{3}$} & \multirow{2}{*}{$\mathrm{Co}_{3} \mathrm{O}_{4}$} & \multicolumn{4}{|c|}{ Mass fraction (\%) } & \multirow{2}{*}{ Significance } \\
\hline & & & & $\mathrm{Fe}_{2} \mathrm{O}_{3}$ & $\mathrm{Fe}$ & $\mathrm{Mg}$ & $\mathrm{Mn}$ & \\
\hline $1 \#$ & 100 & 0 & 0 & 0 & 0 & 0 & 0 & Blank test \\
\hline $2 \#$ & 98 & 2 & 0 & 0 & & & & \\
\hline 3\# & & 0 & 2 & 0 & & & & \\
\hline $4 \#$ & & 0 & 0 & 2 & & & & \\
\hline $5 \#$ & 97 & 3 & 0 & 0 & & & & \\
\hline $6 \#$ & & 0 & 3 & 0 & & & & \\
\hline 7\# & & 0 & 0 & 3 & & & & \\
\hline 8\# & 96 & 4 & 0 & 0 & & & & \\
\hline 9\# & & 0 & 4 & 4 & & & & Analyze the influence of oxides on the thermal decomposition temperature range \\
\hline $10 \#$ & & 0 & 0 & 0 & & & & and rate of sodium chlorate \\
\hline $11 \#$ & 95 & 5 & 0 & 0 & & & & \\
\hline $12 \#$ & & 0 & 5 & 0 & & & & \\
\hline $13 \#$ & & 0 & 0 & 5 & & & & \\
\hline $14 \#$ & 94 & 6 & 0 & 0 & & & & \\
\hline $15 \#$ & & 0 & 6 & 0 & & & & \\
\hline $16 \#$ & & 0 & 0 & 6 & & & & \\
\hline $17 \#$ & 93 & 0 & 5 & 0 & 2 & 0 & 0 & \\
\hline $18 \#$ & & & & & 0 & 2 & 0 & \\
\hline 19\# & & & & & 0 & 0 & 2 & \\
\hline $20 \#$ & 91 & & & & 4 & 0 & 0 & \\
\hline $21 \#$ & & & & & 0 & 4 & 0 & \\
\hline $22 \#$ & & & & & 0 & 0 & 4 & Analyze the effect of mixing metal and $\mathrm{Co}_{3} \mathrm{O}_{4}(5 \%)$ on the effective oxygen \\
\hline 23\# & 89 & & & & 6 & 0 & 0 & production efficiency of sodium chlorate thermal decomposition \\
\hline 24\# & & & & & 0 & 6 & 0 & \\
\hline 25\# & & & & & 0 & 0 & 6 & \\
\hline $26 \#$ & 87 & & & & 8 & 0 & 0 & \\
\hline $27 \#$ & & & & & 0 & 8 & 0 & \\
\hline 28\# & & & & & 0 & 0 & 8 & \\
\hline
\end{tabular}

TABLE 2: Quality of the sample required for the experiment.

\begin{tabular}{lccccc}
\hline Materials & $\mathrm{NaClO}_{3}$ & $\mathrm{Mn}$ & $\mathrm{Co}_{3} \mathrm{O}_{4}$ & Kaolin & Total \\
\hline Weight $(\mathrm{g})$ & 274.2 & 18.7 & 15.6 & 9.5 & 318 \\
\hline
\end{tabular}

temperature of the test was $25 \pm 3^{\circ} \mathrm{C}$, target temperature was $750^{\circ} \mathrm{C}$, heating rate was $20^{\circ} \mathrm{C} / \mathrm{min}$, test gas was $\mathrm{Ar}$, and flow rate was $40 \mathrm{~mL} / \mathrm{min}$.

2.2.3. Oxygen Candle Reaction Experiment. Based on the previous research conclusions, the oxygen candle sample $\left(86 \% \mathrm{NaClO}_{3}, 6 \% \mathrm{Mn}, 5 \% \mathrm{Co}_{3} \mathrm{O}_{4}\right.$, and $3 \%$ kaolin) used in this experiment had an inner diameter of $10 \mathrm{~mm}$, an outer diameter of $60 \mathrm{~mm}$, and a height of $64.5 \mathrm{~mm}$. The weight of a single sample was $318 \mathrm{~g}$. The oxygen candle sample was placed in the reaction device, and silica aerogel felt was placed in the heat insulation structure as the heat insulation material; subsequently, this assembly was connected to the test instrument. The oxygen candle was placed in a closed box with a volume of $216 \mathrm{~L}$, the remote ignition method was used to ignite it, and the Anpal multifunctional gas detector was used to monitor the gas concentration and oxygen production rate changes during the oxygen supply process of the oxygen candle. The gas detector data transmission module was used to output and analyze the experimental data as shown in Figure 3.

\section{Results and Discussion}

3.1. $\mathrm{NaClO}_{3}$ Pyrolysis Reaction Analysis. The combined thermogravimetric experiment and $1 \#$ sample were used to analyze the thermal decomposition reaction process of pure $\mathrm{NaClO}_{3}$; the thermogravimetric (TG) curve obtained is shown in Figure 4 as a blank test. Pure $\mathrm{NaClO}_{3}$ began to decompose at approximately $520^{\circ} \mathrm{C}$, TG curve began to decrease, and thermal decomposition reaction ended at approximately $600^{\circ} \mathrm{C}$. The TG curve obtained was smooth, indicating that the pyrolysis process of pure $\mathrm{NaClO}_{3}$ is relatively stable. The main reaction equation is shown in the following equation $[13,14]$. By comparing the process and regular pattern of the thermal decomposition reaction between the test sample and pure $\mathrm{NaClO}_{3}$, the effect of the catalyst and metal on the thermal decomposition reaction of $\mathrm{NaClO}_{3}$ was determined.

$$
2 \mathrm{NaClO}_{3} \stackrel{\Delta}{\longrightarrow} 2 \mathrm{NaCl}+3 \mathrm{O}_{2}
$$

The oxychloride anode comprises sodium oxychloride, metal fuel, oxide catalyst, and binder. Past research evidence shows that oxides can be catalysts, and the characteristic properties of metal oxide reactions form thermal reactions to provide energy. This study analyzed the effects of three oxides $\left(\mathrm{Co}_{2} \mathrm{O}_{3}, \mathrm{Co}_{3} \mathrm{O}_{4}\right.$, and $\left.\mathrm{Fe}_{2} \mathrm{O}_{3}\right)$ and three metals ( $\mathrm{Fe}, \mathrm{Mg}$, and $\mathrm{Mn}$ ) on the thermal decomposition of $\mathrm{NaClO}_{3}$ [15]. 


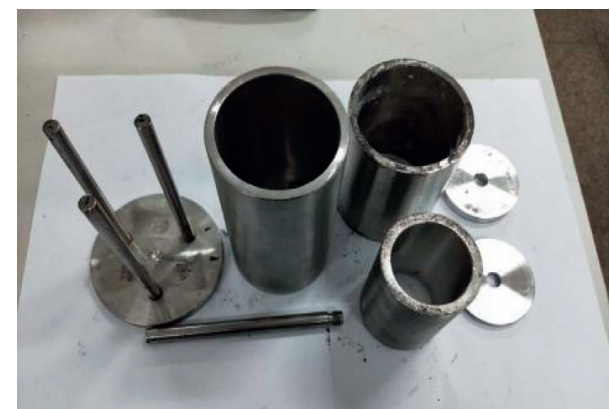

Figure 1: Pressing mold of hollow structure oxygen candle.

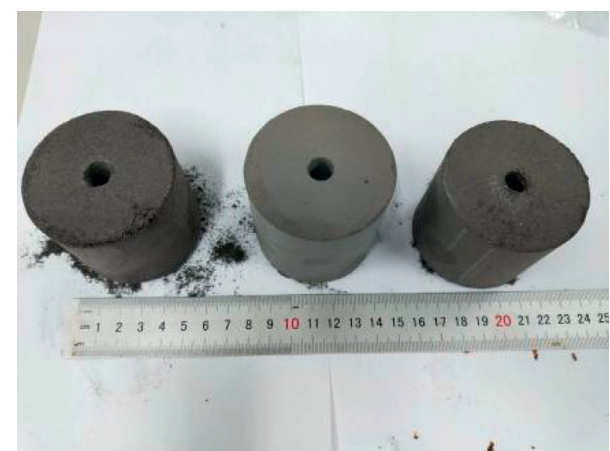

FIGURE 2: Oxygen candle test sample.

\subsection{Analysis of the Influence of Oxide on the Thermal Decomposition Reaction of $\mathrm{NaClO}_{3}$}

3.2.1. Analysis of the Influence of Oxide on the Thermal Decomposition Temperature of $\mathrm{NaClO}_{3}$. According to the ICTAC regulations [12], the pyrolysis rate (TG) in the thermogravimetric test can be calculated by equation (4).

$$
\mathrm{TG}=\frac{m_{t}}{m_{0}},
$$

where $m_{t}$ is the mass of the sample at time $t, m_{0}$ is the mass of the sample at the beginning of pyrolysis.

Three oxides of $\mathrm{Co}_{2} \mathrm{O}_{3}, \mathrm{Co}_{3} \mathrm{O}_{4}$, and $\mathrm{Fe}_{2} \mathrm{O}_{3}$ were selected as catalysts, and the mass fractions of each oxide were $2 \%$, $3 \%, 4 \%, 5 \%$, and $6 \%$, and the 15 samples above are used to carry out the $\mathrm{NaClO}_{3}$ thermal decomposition reaction test. The thermogravimetric curve of each sample is shown in Figure 5. After adding the oxides $\left(\mathrm{Co}_{2} \mathrm{O}_{3}, \mathrm{Co}_{3} \mathrm{O}_{4}\right.$, and $\left.\mathrm{Fe}_{2} \mathrm{O}_{3}\right)$ to $\mathrm{NaClO}_{3}$, the temperature ranges for the initiation and termination of the thermal decomposition reaction were $348-552^{\circ} \mathrm{C}\left(\mathrm{Co}_{2} \mathrm{O}_{3}\right), 260-450^{\circ} \mathrm{C}\left(\mathrm{Co}_{3} \mathrm{O}_{4}\right)$, and $366-558^{\circ} \mathrm{C}$ $\left(\mathrm{Fe}_{2} \mathrm{O}_{3}\right)$, respectively. For the same oxide, the temperature and range of the starting and ending reaction of the thermal decomposition reaction decreased with the increase in the oxide content. Among them, the oxide mass fractions of 5\% and $6 \%$ did not significantly effect on the temperature and range of the thermal decomposition reaction. The order of the lowering effect of the three oxide catalysts on the pyrolysis temperature of $\mathrm{NaClO}_{3}$ is $\mathrm{Co}_{3} \mathrm{O}_{4}>\mathrm{Co}_{2} \mathrm{O}_{3}>\mathrm{Fe}_{2} \mathrm{O}_{3}$. Therefore, $\mathrm{Co}_{3} \mathrm{O}_{4}$ is the best catalyst to control the temperature range of the thermal decomposition reaction.
3.2.2. Analysis of the Influence of Oxides on the Thermal Decomposition Rate of $\mathrm{NaClO}_{3}$. The conversion rate $(\alpha)$ in the thermogravimetric test can be calculated by the following equation.

$$
\alpha=\frac{m_{0}-m_{t}}{m_{0}-m_{f}},
$$

where $m_{0}$ is the mass of the sample at the beginning of pyrolysis, $m_{t}$ is the mass of the sample at time $t$, and $m_{f}$ is the mass of the sample at the end of pyrolysis.

In this study, the temperature pyrolysis characteristic temperature corresponding to the conversion rates $\alpha=0.1$ and $\alpha=0.9$ was recorded as $T_{0.1}$ and $T_{0.9}$, i.e., pyrolysis starting temperature and ending temperature, respectively. The characteristic temperature is shown in Figure 6. The difference between the two is regarded as the pyrolysis interval $\left(\Delta T=T_{0.9}-T_{0.1}\right)$. At a constant heating rate of $20^{\circ} \mathrm{C} /$ min, the smaller the $\Delta \mathrm{T}$, the shorter the pyrolysis time of the sample, and the faster the pyrolysis rate and vice versa.

It can be seen from Figure 6 that the initial reaction temperature $T_{0.1}$ of $\mathrm{NaClO}_{3}$ decreases with the increase of the oxide mass fraction. Among the three oxides, $T_{0.1 \text { min }}$ was $260^{\circ} \mathrm{C}\left(\mathrm{Co}_{3} \mathrm{O}_{4}-6 \%\right)$ and $\mathrm{T}_{0.1 \max }$ was $\left(\mathrm{Fe}_{2} \mathrm{O}_{3}-2 \%\right)$. The $\mathrm{NaClO}_{3}$ termination reaction temperature $T_{0.9}$ decreased with the increase of the oxide mass fraction. $T_{0.9 \min }$ was $306^{\circ} \mathrm{C}$ $\left(\mathrm{Co}_{3} \mathrm{O}_{4}, 6 \%\right)$, and $T_{0.9 \max }$ was $559^{\circ} \mathrm{C}\left(\mathrm{Fe}_{2} \mathrm{O}_{3}, 2 \%\right)$. For the same oxide, as the mass fraction increased, $T_{0.1}$ and $T_{0.9}$ gradually decreased; however, when the mass fraction was between $4 \%$ and $6 \%$, the effect on $T_{0.1}$ and $T_{0.9}$ was small, that is, the catalytic effect change was relatively low.

By analyzing the influence of oxides on $T_{0.1}$ and $T_{0.9}$, it was observed that $\Delta \mathrm{T}$ increases with the increase of the mass fraction of $\mathrm{Co}_{2} \mathrm{O}_{3}$, decreases with the increase of the $\mathrm{Co}_{3} \mathrm{O}_{4}$ content, and decreases with the increase of the mass fraction of $\mathrm{Fe}_{2} \mathrm{O}_{3}$. The smaller the $\Delta \mathrm{T}$, the faster the pyrolysis rate. Therefore, among the three metal oxides, $\mathrm{Co}_{3} \mathrm{O}_{4}$ (5-6\%) corresponded to the smallest $\Delta \mathrm{T}$, which was $46.2^{\circ} \mathrm{C}$, which is $14^{\circ} \mathrm{C}$ lower than that of pure $\mathrm{NaClO}_{3}$. Consequently, $\mathrm{Co}_{3} \mathrm{O}_{4}$ has the best effect on accelerating the decomposition rate of $\mathrm{NaClO}_{3}$ thermal decomposition reaction.

\subsubsection{Determination of High-Efficiency Oxide Catalyst} Components. According to the analysis of the influence of oxides on the thermal decomposition reaction, it can be seen that among the three oxide catalysts, $\mathrm{Co}_{3} \mathrm{O}_{4}(5-6 \%)$ reduces the temperature range of the initiation and termination of the thermal decomposition reaction and has the best effect on accelerating the rate of thermal decomposition reaction. The corresponding $T_{0.1}$ was $260^{\circ} \mathrm{C}, T_{0.9}$ was $306.2^{\circ} \mathrm{C}$, and $\Delta \mathrm{T}$ was $46.2^{\circ} \mathrm{C}$; the catalytic effect did not change significantly within this range. Therefore, to increase the weight of $\mathrm{NaClO}_{3}$ in the thermal decomposition reaction mixture and ensure more oxygen generation, the $\mathrm{Co}_{3} \mathrm{O}_{4}(5 \%)$ was selected in this study.

\subsection{Analyzing the Coupling Effect of Metal Oxide on Effective} Oxygen Production Rate. Based on the previously reported studies [9-13], we selected four different proportions (2\%, 


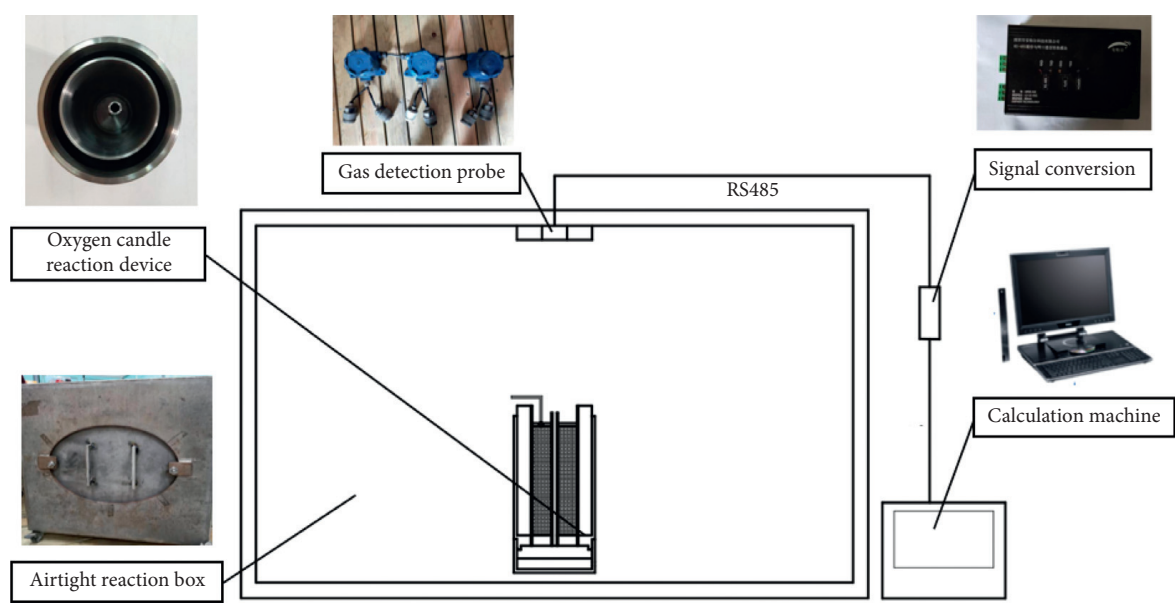

Figure 3: Connection diagram of the oxygen candle oxygen test equipment.

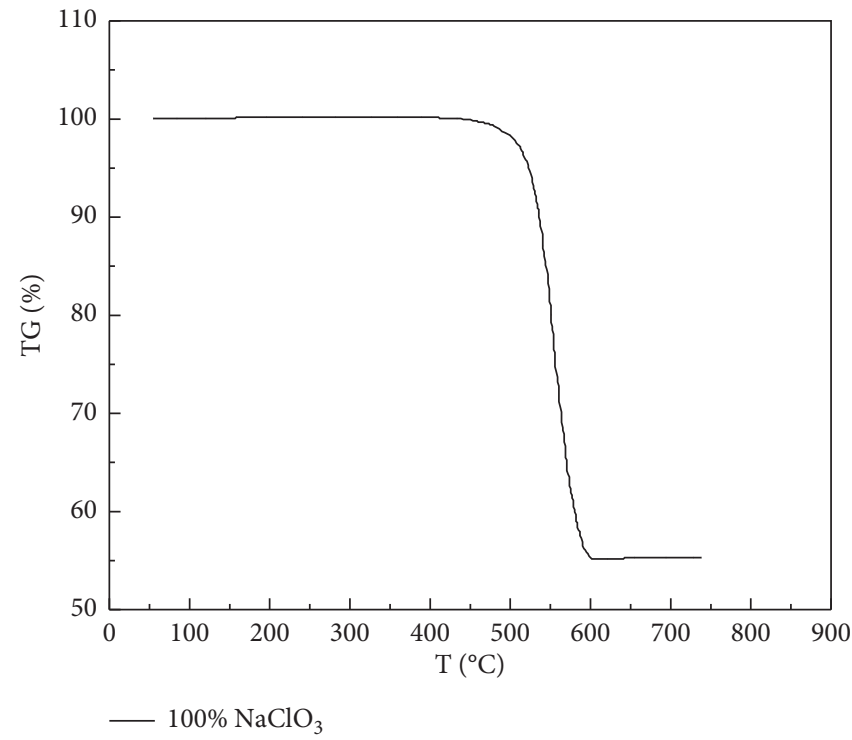

Figure 4: TG curve of thermal decomposition reaction of $\mathrm{NaClO}_{3}$.

$4 \%, 6 \%$, and $8 \%$ ) of three metals ( $\mathrm{Fe}, \mathrm{Mg}$, and $\mathrm{Mn}$ ) mixed with $\mathrm{Co}_{3} \mathrm{O}_{4}(5 \%)$ and analyzed the metal oxide effect on the thermal decomposition reaction of $\mathrm{NaClO}_{3}$. The effective oxygen production efficiency of 17-28\# (a total of 12) samples can be calculated as follows:

$$
\begin{aligned}
N_{\mathrm{O}_{2}} & =\frac{Q_{A \mathrm{O}_{2}}}{Q_{\mathrm{TO}_{2}}}, \\
Q_{A \mathrm{O}_{2}} & =\mathrm{TG} \times m_{0} \times \frac{V_{\mathrm{O}_{2}}}{m_{\mathrm{O}_{2}}}, \\
Q_{\mathrm{TO}_{2}} & =\frac{m_{0} \times \omega_{\mathrm{NaClO}_{3}}}{m_{\mathrm{NaClO}_{3}}} \times \frac{3}{2} \times V_{\mathrm{O}_{2}},
\end{aligned}
$$

where $\mathrm{N}_{\mathrm{O} 2}$ is the effective oxygen production efficiency, $Q_{\mathrm{AO} 2}$ is the actual oxygen production, $Q_{\mathrm{TO} 2}$ is the theoretical oxygen production, TG is the weight loss ratio of the sample, $m_{0}$ is the initial mass of the sample, $\mathrm{V}_{\mathrm{O} 2}$ is the volume of
$1 \mathrm{~mol} \mathrm{O}_{2}$ under standard conditions, which is $2.24 \times 10^{4} \mathrm{~mL}$, $m_{\mathrm{O} 2}$ is the mass of $1 \mathrm{~mol}$ of $\mathrm{O}_{2}$ under the standard condition, which is $3.2 \times 10^{4} \mathrm{mg}, \mathrm{NaClO}_{3}$ is the mass fraction of $\mathrm{NaClO}_{3}$ in the sample, and $m_{\mathrm{NaClO}}$ is the mass of $1 \mathrm{~mol}$ of $\mathrm{NaClO}_{3}$ under the standard condition, which is $1.061 \times 105 \mathrm{mg}$.

Figure 7 shows that when single metal $(2 \%, 4 \%, 6 \%$, and $8 \%)$ is added, the corresponding effective oxygen production efficiency $\left(\mathrm{N}_{\mathrm{O} 2}\right)$ of $\mathrm{Fe}(4 \%), \mathrm{Mg}(8 \%)$, and $\mathrm{Mn}(6 \%)$ is higher, which is $96.5 \%, 97.2 \%$, and $97.8 \%$, respectively. For the same metal mass fraction, $\mathrm{N}_{\mathrm{O} 2}$ of $2 \%(\mathrm{Mn}), 4 \%(\mathrm{Fe}), 6 \%(\mathrm{Mn})$, and $8 \%(\mathrm{Mg})$ is higher, which is $95.1 \%, 96.5 \%, 97.8 \%$, and $97.2 \%$, respectively. Among these, $\mathrm{N}_{\mathrm{O} 2}$ of $\mathrm{Mg}(6 \%)-\mathrm{Co}_{3} \mathrm{O}_{4}(5 \%)$ is the highest, which is $97.8 \%$. Therefore, $\mathrm{Mn}(6 \%)-\mathrm{Co}_{3} \mathrm{O}_{4}(5 \%)$ was selected as the metal fuel and catalyst of the oxygen candle body.

3.4. Experimental Analysis of the Oxygen Supply Reaction of Oxygen Candle. The oxygen supply reaction experiment can obtain the oxygen candle $\mathrm{O}_{2}$ production rate curve 


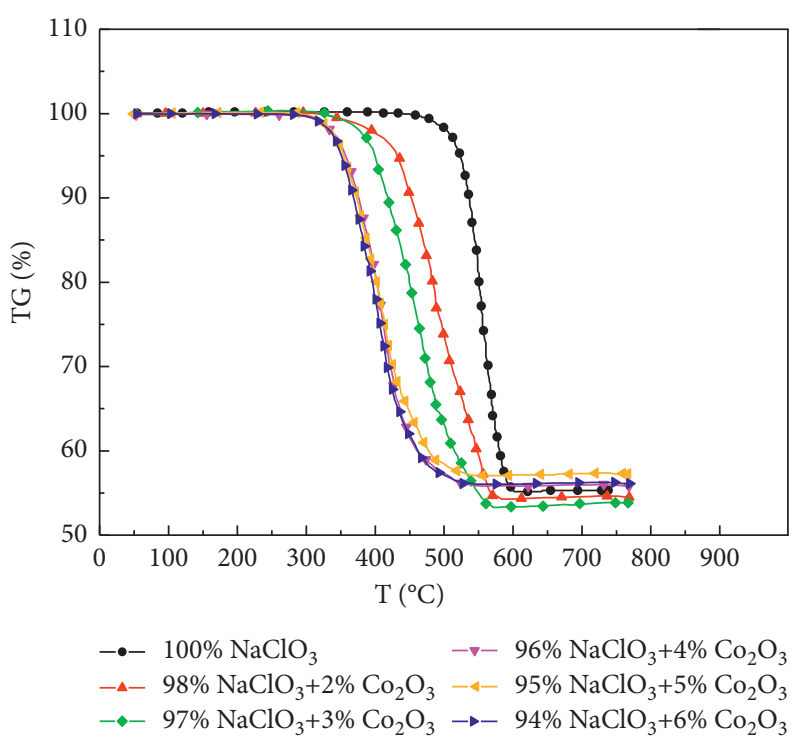

(a)

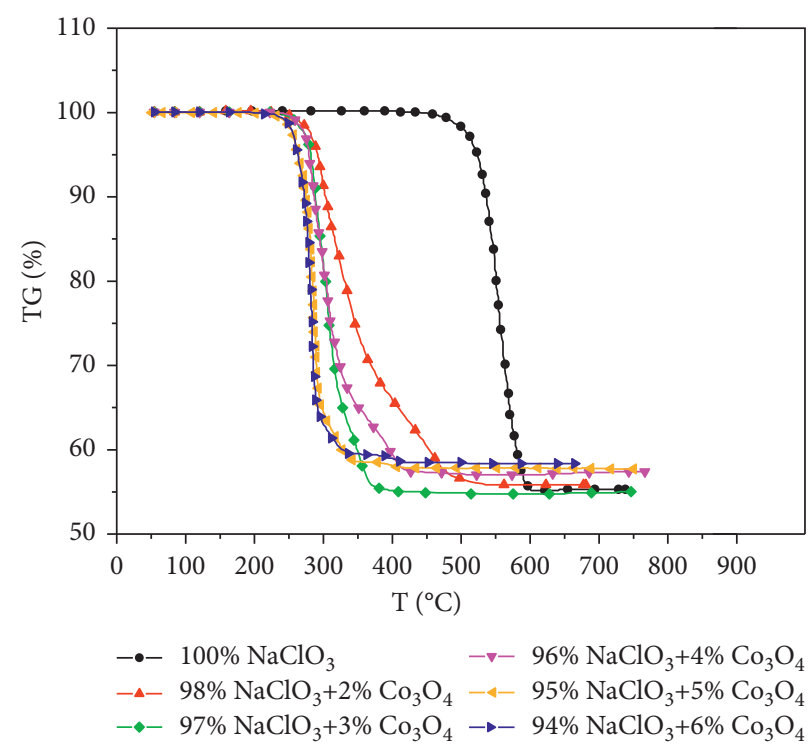

(b)

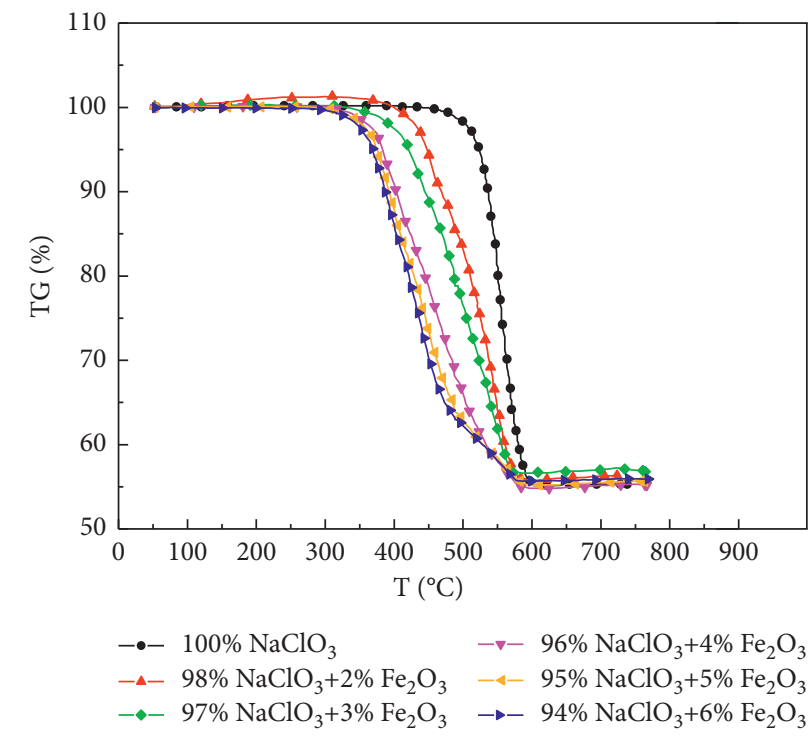

(c)

Figure 5: $\mathrm{NaClO}_{3}$ oxide TG curve. (a) $\mathrm{NaClO}_{3}-\mathrm{Co}_{2} \mathrm{O}_{3}$ TG curve. (b) $\mathrm{NaClO}_{3}-\mathrm{Co}_{3} \mathrm{O}_{4}$ TG curve. (c) $\mathrm{NaClO}_{3}-\mathrm{Fe} 2 \mathrm{O}_{3}$ TG curve.

(Figure 8) and the oxygen candle $\mathrm{O}_{2}$ concentration curve (Figure 9). The experiment was carried out for $53 \mathrm{~min}$, and the entire oxygen supply reaction was divided into four stages: the initial reaction stage $(0-6 \mathrm{~min})$, rapid rise stage (6-13 $\mathrm{min})$, rapid decline stage (13-17 $\mathrm{min})$, and stable endstage (17-53 $\mathrm{min})$. In the initial reaction stage, the oxygen production rate in the reaction space was $0 \mathrm{~L} / \mathrm{min}$, and the oxygen concentration was maintained at $20 \%$. This shows that the oxygen candle reacted slowly in the initial stage, and the gas monitoring system did not detect the generation of oxygen, and thus, the oxygen concentration in the reaction space did not change significantly. In the rapid rise stage, the oxygen production rate in the experimental space increased rapidly from 0 to $17.28 \mathrm{~L} / \mathrm{min}$, and the oxygen concentration reached the peak value of $50 \%$, indicating that the rapid reaction at this stage resulted in a large amount of oxygen, and the gas monitoring system detected a large amount of oxygen around the oxygen candle. During the rapid decline stage, the oxygen production rate in the experimental space decreased rapidly from 17.28 to $0.5 \mathrm{~L} / \mathrm{min}$, and the oxygen concentration decreased to $33 \%$. This shows that the oxygen supply reaction at this stage entered a slow stage, and the gas generated in the rapid ascent stage is gradually and evenly distributed in the test space; in addition, the oxygen concentration monitored by the gas monitoring system decreases gradually. At the stable end-stage, the oxygen production rate in the experimental space gradually tended to $0 \mathrm{~L} / \mathrm{min}$, and the oxygen concentration was maintained at $33 \%$. This shows that the oxygen supply reaction of the oxygen candle at this stage is over, and the gas monitoring system shows that the space oxygen vacancy remains unchanged. 


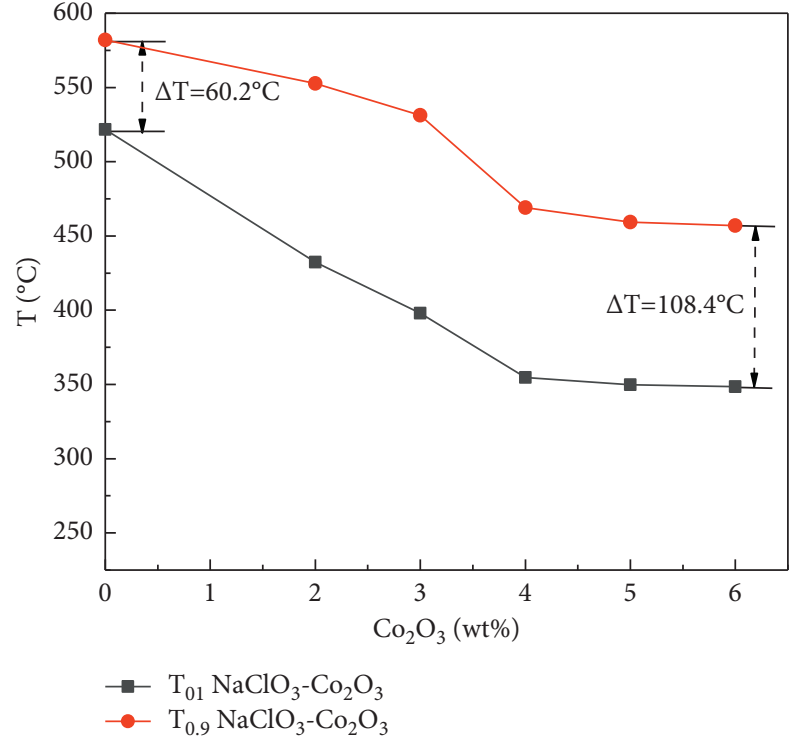

(a)

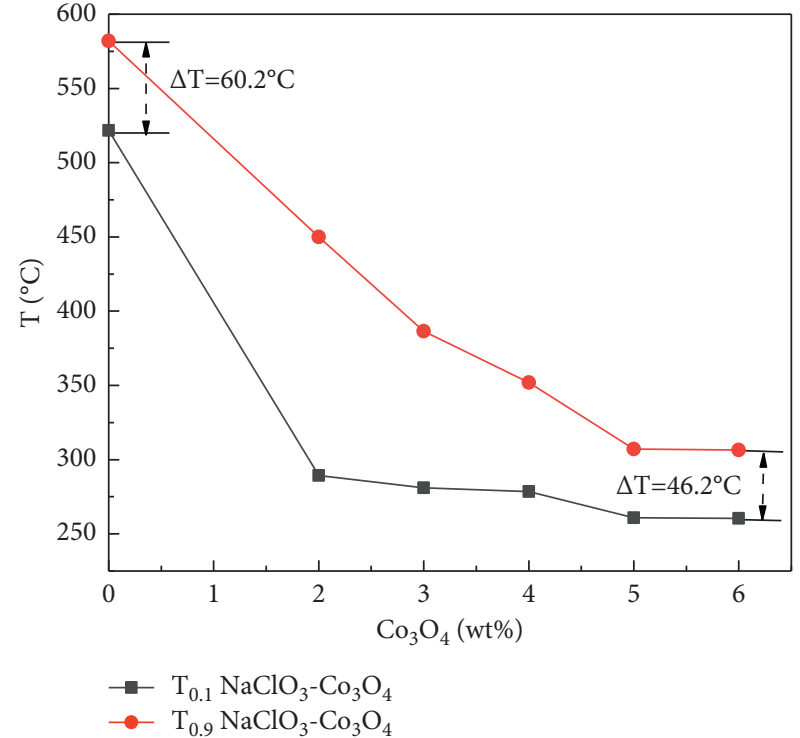

(b)

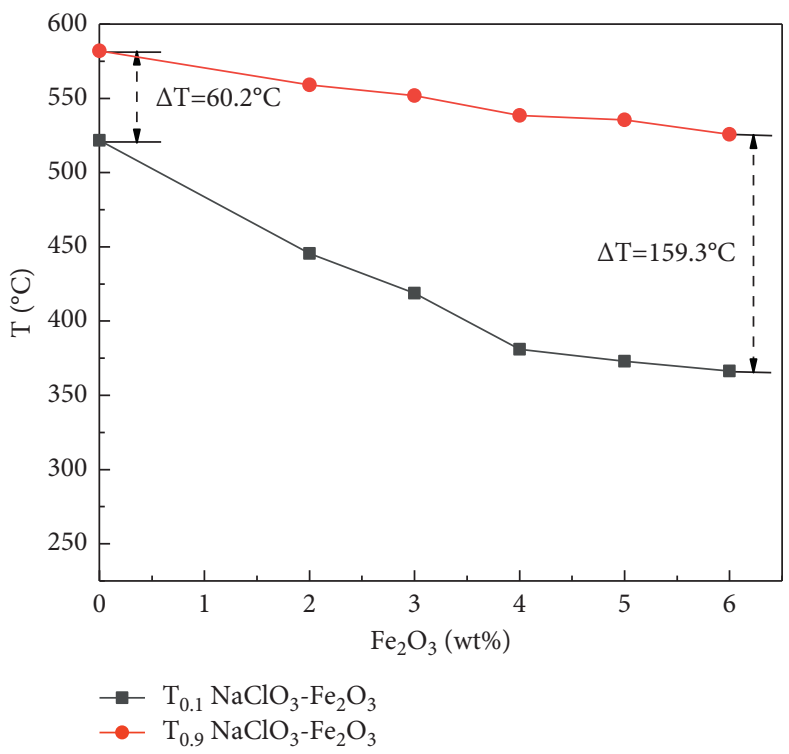

(c)

Figure 6: $\mathrm{NaClO}_{3}$ oxide pyrolysis characteristic temperature curve. (a) $\mathrm{NaClO}_{3}-\mathrm{Co}_{2} \mathrm{O}_{3}$ pyrolysis characteristic temperature curve. (b) $\mathrm{NaClO}_{3}-\mathrm{Co}_{3} \mathrm{O}_{4}$ pyrolysis characteristic temperature curve. (c) $\mathrm{NaClO}_{3}-\mathrm{Fe}_{2} \mathrm{O}_{3}$ pyrolysis characteristic temperature curve.

According to the following equations, the actual oxygen production of the oxygen candle oxygen supply device was $28 \mathrm{~L}$, and the effective oxygen production rate was $53.6 \%$.

$$
\begin{aligned}
N_{E} & =\frac{V_{A}}{V_{T}}, \\
V_{i} & =\left(C_{s}-C_{i}\right) \times V_{b},
\end{aligned}
$$

where $N_{E}$ is the effective oxygen production rate of the oxygen candle, $V_{A}$ is the actual oxygen production of the oxygen candle, $V_{T}$ is the theoretical oxygen production of the oxygen candle, which is $52.2 \mathrm{~L}, C_{s}$ is the oxygen concentration in the test space during the stable phase of the oxygen supply reaction of the oxygen candle, $C_{i}$ is the oxygen concentration in the test space at the initial stage of the candle oxygen supply reaction, and $V_{b}$ is the test space volume.

According to the following equation, the average oxygen production rate during the oxygen candle oxygen experiment was $1.647 \mathrm{~L} / \mathrm{min}$.

$$
v=\frac{V_{A}}{T_{A}},
$$

where $v$ is the average oxygen production rate in the oxygen candle oxygen experiment, and $T_{A}$ is the reaction time of the oxygen candle in the oxygen candle oxygen experiment, which is $17 \mathrm{~min}$. 


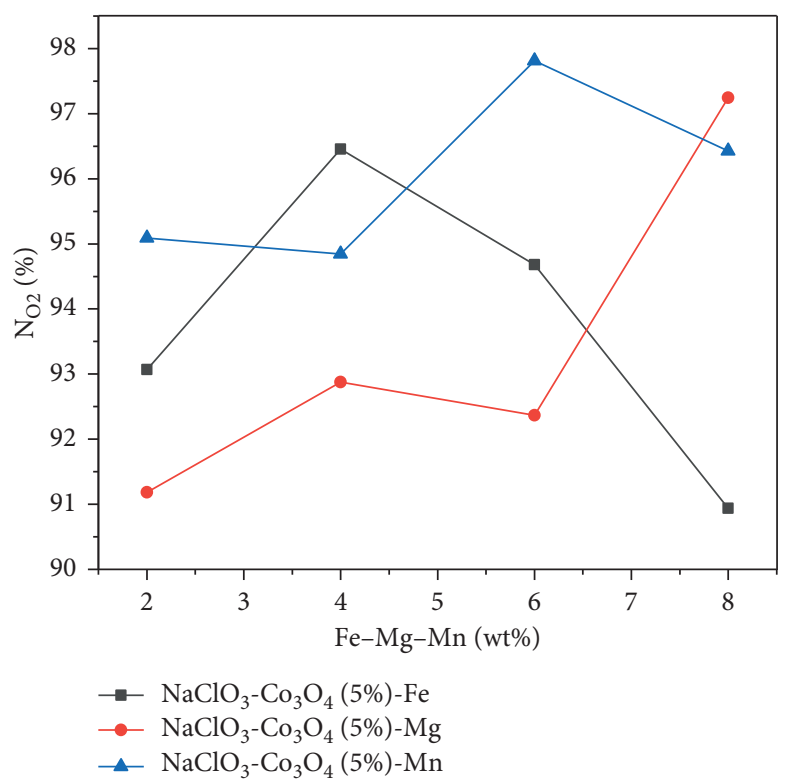

Figure 7: $\mathrm{NaClO}_{3}-5 \% \mathrm{Co}_{3} \mathrm{O}_{4}$ metal effective oxygen production efficiency curve.

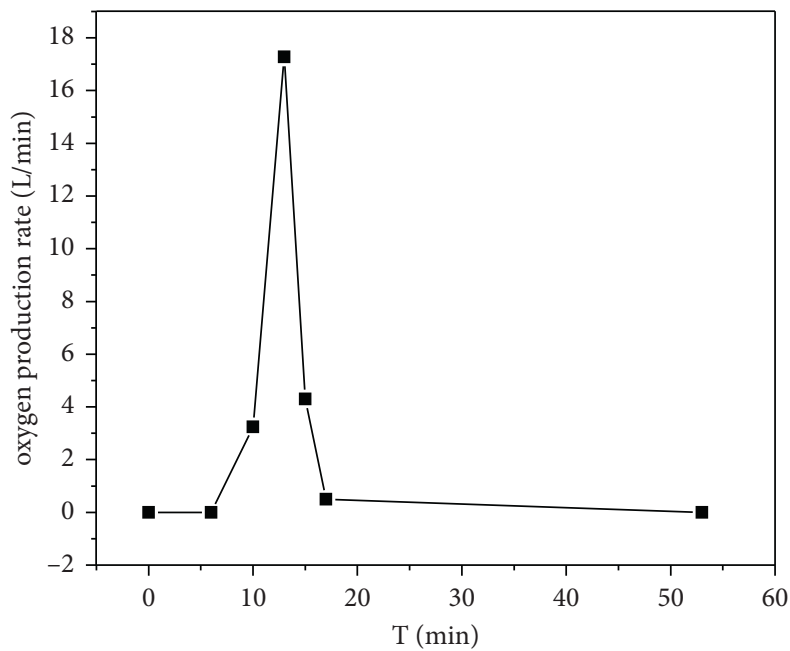

- - oxygen production rate

FIGURE 8: Oxygen candle $\mathrm{O}_{2}$ production rate curve of test space.

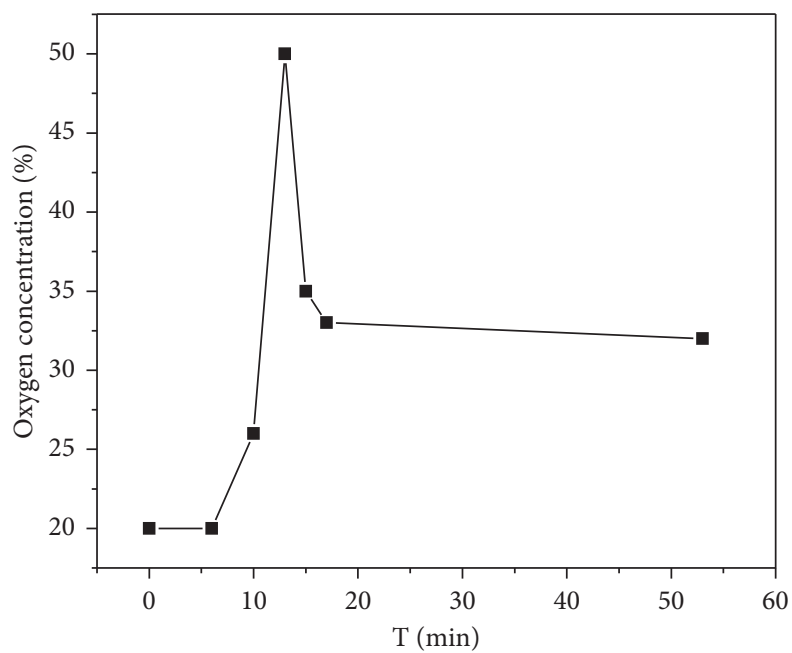

-匹- Oxygen concentration

Figure 9: Oxygen candle $\mathrm{O}_{2}$ concentration curve of test space. 


\section{Conclusion}

(1) When the oxide catalysts $\left(\mathrm{Co}_{2} \mathrm{O}_{3}, \mathrm{Co}_{3} \mathrm{O}_{4}\right.$, and $\mathrm{Fe}_{2} \mathrm{O}_{3}$ ) were added separately, the pyrolysis temperature of $\mathrm{NaClO}_{3}$ reduced significantly, which decreased gradually with an increase in the mass fraction of the catalyst. When the mass fraction of the catalyst reached $4-6 \%$, the pyrolysis temperature of $\mathrm{NaClO}_{3}$ remains unchanged. The thermal decomposition temperature remained unchanged. The lowering effect of the three different oxides on the pyrolysis temperature of $\mathrm{NaClO}_{3}$ was in the following order: $\mathrm{Co}_{3} \mathrm{O}_{4}>\mathrm{Co}_{2} \mathrm{O}_{3}>\mathrm{Fe}_{2} \mathrm{O}_{3}$. The order of pyrolysis rate was $\mathrm{Co}_{3} \mathrm{O}_{4}>\mathrm{Co}_{2} \mathrm{O}_{3}>\mathrm{Fe}_{2} \mathrm{O}_{3}$, and finally, $\mathrm{Co}_{3} \mathrm{O}_{4}(5 \%)$ was selected as the catalytic high-efficiency agent.

(2) When $2 \%, 4 \%, 6 \%$, and $8 \%$ of metal ( $\mathrm{Fe}, \mathrm{Mg}$, and $\mathrm{Mn})-\mathrm{Co}_{3} \mathrm{O}_{4}(5 \%)$ were added, the order of the effective oxygen production efficiency of Fe metal for $\mathrm{NaClO}_{3}$ is $\mathrm{Fe}(4 \%)>\mathrm{Fe}(6 \%)>\mathrm{Fe}(2 \%)>\mathrm{Fe}$ $(8 \%)$, the order of the effective oxygen production efficiency of $\mathrm{Mg}$ metal for $\mathrm{NaClO}_{3}$ is $\mathrm{Mg}(8 \%)>$ $\operatorname{Mg}(4 \%)>\operatorname{Mg}(6 \%)>M g(2 \%)$, the order of the effective oxygen production efficiency of $\mathrm{Mn}$ metal for $\mathrm{NaClO}_{3}$ is $\mathrm{Mn}(6 \%)>\mathrm{Mn}(8 \%)>\mathrm{Mn}$ $(4 \%)>\mathrm{Mn}(2 \%)$, and the order of the effective oxygen production efficiency of different metals for $\mathrm{NaClO}_{3}$ is $\mathrm{Mn}(6 \%)>\mathrm{Mg}(8 \%)>\mathrm{Fe}(4 \%)$. Finally, $\mathrm{Mn}(6 \%)-\mathrm{Co}_{3} \mathrm{O}_{4}(5 \%)$ was selected as the metal fuel and catalyst of the oxygen candle body, with the highest oxygen production efficiency of $97.8 \%$.

(3) Oxygen candle oxygen supply experiment showed that the optimized oxygen candle prescription $(86 \%$ of $\mathrm{NaClO}_{3}, 6 \%$ of $\mathrm{Mn}, 5 \%$ of $\mathrm{Co}_{3} \mathrm{O}_{4}$, and $3 \%$ of kaolin) oxygen supply reaction is divided into four stages: initial reaction stage $(0-6 \mathrm{~min})$, rapid rise stage $(6-13 \mathrm{~min})$, rapid decline stage $(13-17 \mathrm{~min})$, and stable end-stage (17-53 min). The actual oxygen production was $28 \mathrm{~L}$, average oxygen production rate was $1.647 \mathrm{~L} / \mathrm{min}$, and the effective oxygen production rate of the oxygen candle was 53.6\%, which confirm an increase of $9 \%$ compared to that reported previously.

(4) Although the optimal ratio of oxygen candle and its actual oxygen supply efficiency are obtained through experiments, the specific equipment for oxygen supply by oxygen candle is not studied. In the future research, the basic theoretical research of oxygen supply by oxygen candle should be combined with the practical application equipment to realize the transformation of achievements.

\section{Data Availability}

The data used to support the findings of this study are available from the corresponding author upon request.

\section{Conflicts of Interest}

The authors declare that they have no conflicts of interest.

\section{Acknowledgments}

This work was supported by the National Natural Science Foundation of China (51504017) and the funds for basic scientific research operations of Central Universities in China (FRF-RDRY-20-028).

\section{References}

[1] Y. Zhang, G. Kshirsagar, J. E. Ellison, and J. C. Cannon, "Catalytic effects of metal oxides on the thermal decomposition of sodium chlorate," Thermochimica Acta, vol. 228, pp. 147-154, 1993.

[2] E. Shafirovich, A. Garcia, A. K. Narayana Swamy, D. J. Mast, and S. D. Hornung, "On feasibility of decreasing metal fuel content in chemical oxygen generators," Combustion and Flame, vol. 159, no. 1, pp. 420-426, 2012.

[3] L.-Z. Jin, S. Wang, S.-C. Liu, and Z. Zhang, "Development of a low oxygen generation rate chemical oxygen generator for emergency refuge spaces in underground mines," Combustion Science and Technology, vol. 187, no. 8, pp. 1229-1239, 2015.

[4] M. A. Machado, D. A. Rodriguez, Y. Aly, M. Schoenitz, E. L. Dreizin, and E. Shafirovich, "Nanocomposite and mechanically alloyed reactive materials as energetic additives in chemical oxygen generators," Combustion and Flame, vol. 161, no. 10, pp. 2708-2716, 2014.

[5] H. Weimin, Y. Jinhai, K. Qingping, X. Baoqing, and L. Xiaofeng, "Analysis on the effect of plateau oxygen supply of oxygen supply device of a certain type of oxygen candle," Occupation and Health, vol. 26, 2014.

[6] J. Lei, G. Chengjun, H. Zaiming, L. Dongliang, L. Shuai, and C. Jun, "Experimental verification of applying chemical oxygen generators in full ocean deeply manned submersible," China Shipbuilding, vol. 62, pp. 153-161, 2021.

[7] W. Shu, J. Longzhe, L. Shuci, and Z. Zheng, "Application of oxygen candles in emergency avoidance systems in non-coal mines," Chinese Journal of Safety Science, vol. 24, no. 4, pp. 166-170, 2014.

[8] E. Shafirovich, C. Zhou, S. Ekambaram, A. Varma, G. Kshirsagar, and J. E. Ellison, "Catalytic effects of metals on thermal decomposition of sodium chlorate for emergency oxygen generators," Industrial \& Engineering Chemistry Research, vol. 46, no. 10, pp. 3073-3077, 2007.

[9] J.-G. Liu, L.-Z. Jin, N. Gao, S.-N. Ou, S. Wang, and W.-X. Wang, "A review on chemical oxygen supply technology within confined spaces: challenges, strategies, and opportunities toward chemical oxygen generators (COGs)," International Journal of Minerals, Metallurgy, and Materials, vol. 26, no. 8, pp. 925-937, 2019.

[10] L. Jianguo, J. Longzhe, G. Na, W. Shu, and Z. Hao, "Catalytic effect of manganese metal particle size in oxygen candle on pyrolysis of sodium chlorate," Chinese Journal of Engineering, vol. 39, no. 8, pp. 1159-1165, 2017.

[11] W. Wang, L. Jin, N. Gao, J. Wang, M. Liu, and A. Demonceau, "The oxygen generation performance of hollow-structured oxygen candle for refuge space," Journal of Chemistry, vol. 2018, Article ID 7469783, 9 pages, 2018.

[12] Sinopec Beijing Yanshan Branch Resin Application Research Institute, Sinopec Qilu Branch Research Institute, China Petroleum and Petrochemical Research Institute \& China Blue 
Chenguang Chengdu Inspection Technology Co., Ltd., Inspection and Quarantine of the People's Republic of China; Standardization Administration of China, 2016.

[13] N. Gao, Y.-Q. Dai, L.-Z. Jin et al., "Effect of metals and Co3O4 on the thermal decomposition reaction of sodium chlorate in an area of refuge," Chemical Papers, vol. 74, no. 10, pp. 3475-3480, 2020.

[14] Academic Press, Catalytic Decomposition of Sodium Chlorate, Academic Press, Cambridge, MA, USA, 1970.

[15] Z. Zheng, "Optimization of the formula of oxygen candles for rescue capsules," Chinese Journal of Safety Science, vol. 23, no. 9, pp. 129-135, 2013. 